\title{
Effect of thoracic epidural analgesia on clinical outcomes following transapical transcatheter aortic valve implantation
}

\author{
Ignacio J Amat-Santos, ${ }^{1}$ Eric Dumont, ${ }^{1}$ Jacques Villeneuve, ${ }^{1}$ Daniel Doyle, ${ }^{1}$ \\ Michel Rheault, ${ }^{1}$ Dominique Lavigne, ${ }^{1}$ Jerôme Lemieux, ${ }^{1}$ André St-Pierre, \\ Michael Mok, ${ }^{1}$ Marina Urena, ${ }^{1}$ Luis Nombela-Franco, ${ }^{1}$ Steve Blackburn, ${ }^{1}$ \\ Mathieu Simon, ${ }^{1}$ Christine Bourgault, ${ }^{1}$ José Luis Carrasco, ${ }^{1}$ Philippe Pibarot, ${ }^{1}$ \\ Melanie Côté, ${ }^{1}$ Robert DeLarochellière, ${ }^{1}$ David J Cohen, ${ }^{2}$ Josep Rodés-Cabau ${ }^{1}$
}

\begin{abstract}
See Editorial p1441
${ }^{1}$ Quebec Heart and Lung Institute, Laval University, Quebec City, Quebec, Canada ${ }^{2}$ Saint Luke's Mid America Heart Institute, University of Missouri-Kansas City, Kansas City, Missouri, USA
\end{abstract}

\section{Correspondence to}

Dr Josep Rodés-Cabau, Quebec Heart Lung Institute, Laval University, 2725 chemin Ste-Foy, G1V 4G5 Quebec city, OC G1V 4G5, Canada; josep. rodes@criucpq.ulaval.ca

Accepted 11 June 2012 Published Online First 11 July 2012

\section{ABSTRACT}

Objective To determine the impact of perioperative thoracic epidural analgesia (TEA) on acute and late outcomes following transapical transcatheter aortic valve implantation (TA-TAVI).

Patients and intervention A total of 135 consecutive patients who underwent TA-TAVI were included. All patients received catheter-based pain control, either via TEA (TEA group, $n=74$ ) or intercostal local analgesia with a catheter placed at the surgical incision site (nonTEA group, $n=61$ ), depending on the preference of the anaesthesiologist responsible for the case.

Main outcome measures Pain level during early postoperative period (verbal rating scale from 1 to 10), 30-day/in-hospital complications and mortality, and 1year mortality.

Results There were no differences in baseline or procedural characteristics between groups except for a lower left ventricular ejection fraction in the TEA group. The maximal pain score related to thoracotomy in the postoperative period was higher in the non-TEA group as compared with the TEA group (4 (IQR: 3-5)) vs 2 (IQR: $1-3), p<0.001)$. Non-TEA was associated with a higher rate of pulmonary complications $(p<0.05$ for nosocomial pneumonia, reintubation and tracheostomy). The 30-day/in-hospital mortality rate was higher in the non-TEA group $(22.9 \%$ vs $2.7 \%$ in the TEA group, $\mathrm{p}<0.001)$. At 1-year follow-up, overall mortality remained higher in the non-TEA group (31.1\%) compared with the TEA group (10.8\%), $p=0.005$. Similar periprocedural and late results were obtained in a propensity score-matched analysis that included 100 matched patients. In the multivariable analysis, STS score $(p=0.027)$ and absence of TEA $(p=0.039)$ were independent predictors of increased cumulative late mortality.

Conclusions TEA provided superior analgesia following TA-TAVI, and was associated with a dramatic reduction in periprocedural respiratory complications, and both, short- and long-term mortality. These results highlight the importance of obtaining optimal analgesia following TA-TAVI to improve the results associated with this procedure.

\section{INTRODUCTION}

The transapical approach (TA) has been widely used as an alternative to the transfemoral approach in those patients with unsuitable iliofemoral vascular access undergoing transcatheter aortic valve implantation (TAVI). ${ }^{1}{ }^{2}$ However, some data have suggested poorer acute and midterm outcomes associated with this approach as compared with the transfemoral approach. ${ }^{3-7}$ This has been partially explained by the higher risk profile of those patients selected for the TA approach, but very few data exist on the potential deleterious consequences of thoracotomy in the very old and high-risk patients who are most commonly selected for TAVI.

Provision of adequate postoperative analgesia is a key determinant of clinical outcomes following thoracic surgery. 8 Thoracotomy may be associated with severe postoperative pain which may lead to a further worsening of pulmonary function and an increased risk of severe pulmonary complications and death. Thoracic epidural analgesia (TEA) has been shown to provide better pain control and improve clinical outcomes following thoracotomy for cardiovascular or thoracic interventions. ${ }^{8-11}$ However, very few data exist on postoperative chest pain and its potential clinical consequences following TA-TAVI, or on the use of TEA in TATAVI procedures. ${ }^{12}$ The objective of our study was, therefore, to evaluate the effects of TEA on reducing postoperative pain and improving clinical outcomes following TA-TAVI.

\section{METHODS}

A total of 135 consecutive patients with severe symptomatic aortic stenosis who underwent TATAVI with a balloon-expandable valve (Edwards SAPIEN or SAPIEN XT, Edwards Lifesciences, Irvine, California, USA) at our institution were included. Details about the TA-TAVI procedure have been extensively explained in previous studies. ${ }^{13}$

Anaesthesia and postoperative analgesia protocol All patients were premedicated with $0.05 \mathrm{mg} / \mathrm{kg}$ of midazolam on the day of the procedure. Induction was done with bolus doses of either ketamine or etomidate and rocuronium, and all patients were intubated orally. Anaesthesia was maintained with 
sevoflurane and continuous infusion or intermittent boluses of midazolam, remifentanil, fentanyl or sufentanil, which were used according to clinical status and procedural requirements.

The decision to place an epidural catheter for perioperative analgesia was determined by the primary anaesthesiologist for the procedure, and depended primarily on his experience and comfort level with the technique. In accordance with the recommendations of the American Society of Regional Anaesthesia and Pain Medicine, ${ }^{14}$ epidural analgesia was not performed in patients with an underlying coagulopathy. The catheter was placed in the T7-T8 intervertebral space, with a 17-gauge epidural needle, and the correct position was verified by the loss of resistance using air or saline. Epidural catheter insertion was performed before the induction of the anaesthesia to allow at least an hour's delay between the puncture and the administration of heparin in order to decrease the risk of an epidural haematoma in case of unrecognised bleeding from the puncture. An initial bolus of bupivacaine (8 cc, 0.25\%) and fentanyl ( $2 \mathrm{cc}, 50 \mu \mathrm{gr} / \mathrm{cc}$ ) was administered immediately before the induction of general anaesthesia, and was followed by a continuous infusion of the two drugs (bupivacaine $0.1 \%$, fentanyl $5 \mu \mathrm{g} / \mathrm{cc}, 0.1 \mathrm{cc} / \mathrm{kg} / \mathrm{hr}$ ) for at least 3 days. The infusion was adjusted depending on pain level and respiratory rate. In those patients without TEA, an intercostal catheter of 17 gauge was inserted inside the surgical wound at the end of the intervention, and ropivacaine $(0.2 \%$, bolus of $15 \mathrm{cc}$, followed by an infusion at $15 \mathrm{cc} / \mathrm{h}$ ) was administered for at least 3 days. The adequacy of pain control was recorded through a verbal rating scale from 0 to 10 and documented in the nursing report sheet every hour until complete pain relief in both groups. Supplemental analgesia with rectal or oral paracetamol, and subcutaneous or intravenous opioids, was administered in both groups as required.

\section{Postoperative and follow-up outcomes}

All periprocedural complications were prospectively recorded and defined according to the VARC criteria. ${ }^{15}$ Patients were on continuous ECG monitoring until hospital discharge, and newonset atrial fibrillation (NOAF) was defined as any episode of AF lasting longer than $30 \mathrm{~s}$. Follow-up was performed by means of clinical visits or telephone contact at 30 days, 6 months and 12 months, and annually thereafter, and was available in 100\% of the study population. Late cardiovascular events were defined according to the VARC criteria. ${ }^{15}$

\section{Statistical analysis}

Group comparisons were performed using Student's t-test or the Wilcoxon test for continuous variables, and $\chi^{2}$ test or Fisher's exact test for categorical variables. A propensity score matching analysis was performed to adjust for the intergroup (TEA vs nonTEA) differences in baseline characteristics caused by the selection bias inherent to the non-randomised nature of the study. By using a logistic regression analysis, the probability of being assigned to TEA versus non-TEA was calculated from baseline and procedural characteristics. Variables exhibiting a $p$ value $<0.20$ in the univariable analysis were included in the logistic regression analysis. Selected variables were age, diabetes, dyslipidemia, chronic obstructive pulmonary disease, STS-PROM score and left ventricular ejection fraction. By using these covariables, a propensity score was calculated for each patient, and patients of the two groups (TEA vs non-TEA) were matched using a one-to-one matching process. The maximum difference of propensity score for a match was established at $10 \%$. Comparable patient groups, including a total of 100 patients
(TEA group: 50 pts, non-TEA group: 50 pts), were identified for analysis. A Cox multivariable analysis including all variables with $p$ value $<0.05$ in the univariable analysis was used to determine the predictive factors of cumulative late mortality. Late outcomes were also assessed by Kaplan-Meier estimates and compared using the log-rank test. The results were considered significant with $\mathrm{p}$ values $<0.05$. Statistical analyses were performed with the statistical package SAS, V.9.2 (SAS Institute Inc).

\section{RESULTS}

The main clinical, echocardiographic and procedural characteristics of the study population and the TEA and non-TEA groups are shown in table 1 . The mean gradient decreased to $12.1 \pm 7.5 \mathrm{~mm} \mathrm{Hg}$, and valve area increased to $1.48 \pm 0.34 \mathrm{~cm}^{2}$ following the intervention ( $p<0.001$ vs baseline for both), with no differences between TEA and non-TEA groups ( $p>0.20$ for both, mean gradient and valve area). Some degree of residual aortic regurgitation was observed in $67 \%$ of the patients, and was trivial or mild in $59 \%$ and mild to moderate in $8 \%$ of the patients, respectively, with no differences $(p=0.63)$ between groups.

\section{Postoperative analgesia and mechanical ventilation times}

Maximal pain scores at different time periods following TATAVI grouped according to the type of postoperative analgesia (TEA vs non-TEA) are shown in figure 1 . The median maximum pain scores during the postoperative period were $2(1-3)$ and 4 $(3-5)$ in the TEA and non-TEA groups, respectively $(p<0.0001)$. The median pain scores during the first $24 \mathrm{~h}$ (TEA: $1(1-2)$, nonTEA: $4(3-5))$, at 24-48 h (TEA: 1 (1-2), non-TEA: $2(2-3))$, at 48-72 h (TEA: $1(0-1)$, non-TEA: $1(1-2))$, and after $72 \mathrm{~h}$ up to hospital discharge (TEA: $0(0-1)$, non-TEA: $1(1-2))$ following the procedure were higher in the non-TEA group as compared with the TEA group ( $p<0.0001$ for all time periods). The catheter for regional analgesia was removed at a median time of 4 (3-4) days, with no differences between groups (TEA: 4 (3-4) days, non-TEA: 4 (3-4) days, $p=1.00)$. After the first 72 h, $98 \%$ of the patients in the TEA group had no or minimal (score $=0-1$ ) surgical wound pain as compared with $64 \%$ of patients in the non-TEA group $(p<0.0001)$. Up to $57 \%$ of the patients in the TEA group presented no surgical wound pain (score=0) compared with only $16 \%$ of the patients in the non-TEA group $(p<0.0001)$. One patient suffered an epidural catheter migration the second day after surgery with no clinical consequences. There were no haemodynamic, bleeding or neurological complications related to epidural or intercostal catheters. The rate of TEA use was similar in the first and second halves of the study period ( $51 \%$ vs $58 \%$, p $=0.54$ ).

The median orotracheal intubation time was $6 \mathrm{~h}(6-8 \mathrm{~h})$, and it was significantly longer in the non-TEA group than in the TEA group $(7(6-24) \mathrm{h}$, vs $6(6-7) \mathrm{h}, \mathrm{p}=0.001)$. In the TEA group, $93.2 \%$ of the patients were extubated within $12 \mathrm{~h}$ following the intervention, as compared with $73.8 \%$ of the patients in the non-TEA group $(p=0.003)$. Orotracheal intubation of $>48 \mathrm{~h}$ was more frequent in the non-TEA group (14.8\%) as compared with the TEA group (2.7\%), $p=0.023$.

\section{Periprocedural events}

The main periprocedural (30-day/in-hospital) events are shown in table 2 . The 30-day/in-hospital mortality rate was $11.9 \%$, and the main characteristics and causes of death of all patients who died within 30 days, or before hospital discharge following TAVI, are summarised in table 3 . Of the 16 patients who died at 30 days, or before hospital discharge, a total of seven patients (44\%) died due to respiratory complications, and all of them 
Table 1 Baseline and procedural characteristics of the study population $(n=135)$, according to the use of thoracic epidural analgesia

\begin{tabular}{|c|c|c|c|c|}
\hline & \multirow[b]{2}{*}{$\begin{array}{l}\text { Study population } \\
\mathrm{n}=135\end{array}$} & \multicolumn{2}{|c|}{ Thoracic epidural analgesia } & \multirow[b]{2}{*}{ p Value } \\
\hline & & $\begin{array}{l}\text { No } \\
n=61\end{array}$ & $\begin{array}{l}\text { Yes } \\
n=74\end{array}$ & \\
\hline \multicolumn{5}{|l|}{ Baseline variables } \\
\hline Age, years & $79 \pm 8$ & $80 \pm 9$ & $78 \pm 8$ & 0.072 \\
\hline Males & $54(40.0)$ & $26(42.6)$ & $29(39.2)$ & 0.600 \\
\hline Diabetes & $51(37.8)$ & $19(31.2)$ & $32(43.2)$ & 0.159 \\
\hline Dyslipidemia & $113(83.7)$ & $48(78.7)$ & $65(87.8)$ & 0.168 \\
\hline Hypertension & $126(93.3)$ & $58(95.1)$ & 68 (91.9) & 0.512 \\
\hline Coronary artery disease & $89(65.9)$ & $38(62.3)$ & $51(68.9)$ & 0.468 \\
\hline Previous myocardial infarction & $57(42.2)$ & $26(42.6)$ & $31(41.9)$ & 1.00 \\
\hline Previous atrial fibrillation & $35(25.9)$ & $15(24.6)$ & $20(27.0)$ & 0.844 \\
\hline Prior CABG & $55(40.7)$ & $23(37.7)$ & $32(43.2)$ & 0.598 \\
\hline Prior stroke & $6(4.4)$ & $2(3.3)$ & $4(5.4)$ & 0.689 \\
\hline Peripheral vascular disease & $60(44.4)$ & $27(44.3)$ & $33(44.6)$ & 1.00 \\
\hline COPD & $44(32.6)$ & $25(40.9)$ & $19(25.7)$ & 0.067 \\
\hline $\mathrm{FEV}_{1}(\%)^{*}$ & $60 \pm 17$ & $58 \pm 17$ & $65 \pm 17$ & 0.336 \\
\hline eGFR $<60 \mathrm{ml} / \mathrm{min}$ & $88(65.2)$ & $38(62.3)$ & $50(67.6)$ & 0.588 \\
\hline STS-PROM score (\%) & $8.4 \pm 4.4$ & $9.2 \pm 5.2$ & $7.7 \pm 3.4$ & 0.121 \\
\hline Frailty & $19(14.1)$ & $9(14.8)$ & $10(13.5)$ & 1.00 \\
\hline Severely calcified or porcelain aorta & $42(31.1)$ & $17(27.9)$ & $25(33.8)$ & 0.576 \\
\hline \multicolumn{5}{|l|}{ Echocardiographic variables } \\
\hline Mean aortic gradient $(\mathrm{mm} \mathrm{Hg})$ & $41 \pm 16$ & $42 \pm 16$ & $40 \pm 17$ & 0.463 \\
\hline Aortic valve area $\left(\mathrm{cm}^{2}\right)$ & $0.63 \pm 0.19$ & $0.62 \pm 0.15$ & $0.64 \pm 0.22$ & 0.650 \\
\hline $\operatorname{LVEF}(\%)$ & $53 \pm 14$ & $56 \pm 13$ & $51 \pm 14$ & 0.047 \\
\hline LVEF $<40$ & $23(17.0)$ & $7(11.5)$ & $16(21.6)$ & 0.167 \\
\hline SPAP (mm Hg) & $44 \pm 14$ & $45 \pm 13$ & $43 \pm 14$ & 0.342 \\
\hline Moderate/severe mitral regurgitation & $41(30.4)$ & $21(34.4)$ & $20(27.0)$ & 0.452 \\
\hline \multicolumn{5}{|l|}{ Procedural variables } \\
\hline \multicolumn{5}{|l|}{ Type of valve } \\
\hline Edward XT & $8(5.9)$ & $3(4.9)$ & $5(6.7)$ & \multirow[t]{2}{*}{0.729} \\
\hline Edward SAPIEN & $128(94.1)$ & $58(95.1)$ & $70(93.2)$ & \\
\hline \multicolumn{5}{|l|}{ Valve size } \\
\hline $23 \mathrm{~mm}$ & $76(56.3)$ & $34(55.7)$ & $42(56.8)$ & \multirow[t]{3}{*}{0.820} \\
\hline $26 \mathrm{~mm}$ & $54(40.0)$ & $24(39.3)$ & $30(40.5)$ & \\
\hline $29 \mathrm{~mm}$ & $5(3.7)$ & $3(4.9)$ & $2(2.7)$ & \\
\hline Procedural success & $129(95)$ & $57(93.4)$ & $73(97.7)$ & 0.175 \\
\hline Valve embolisation & 0 & 0 & $1(1.4)$ & 1.00 \\
\hline Valve in valve & $5(3.7)$ & $4(6.6)$ & $1(1.4)$ & 0.175 \\
\hline Conversion to open heart surgery & $1(0.7)$ & $1(1.6)$ & 0 & 0.452 \\
\hline \multicolumn{5}{|l|}{ Invasive haemodynamic parametres } \\
\hline Cardiac output preimplant (I/min) & $3.41 \pm 1.31$ & $3.44 \pm 1.48$ & $3.39 \pm 1.60$ & 0.860 \\
\hline Cardiac output postimplant (I/min) & $4.19 \pm 1.60$ & $4.13 \pm 1.78$ & $4.25 \pm 1.45$ & 0.702 \\
\hline SPAP preimplant (mm $\mathrm{Hg})$ & $35 \pm 11$ & $34 \pm 11$ & $35 \pm 10$ & 0.483 \\
\hline SPAP postimplant $(\mathrm{mm} \mathrm{Hg})$ & $40 \pm 12$ & $41 \pm 12$ & $39 \pm 12$ & 0.228 \\
\hline SVR preimplant (dyne $\cdot \mathrm{s} / \mathrm{cm}^{5}$ ) & $2035 \pm 808$ & $2039 \pm 763$ & $2031 \pm 849$ & 0.955 \\
\hline SVR postimplant (dyne $\cdot \mathrm{s} / \mathrm{cm}^{5}$ ) & $1694 \pm 769$ & $1728 \pm 709$ & $1665 \pm 820$ & 0.677 \\
\hline PVR preimplant (dyne $\cdot \mathrm{s} / \mathrm{cm}^{5}$ ) & $223 \pm 132$ & $237 \pm 143$ & $211 \pm 121$ & 0.276 \\
\hline PVR postimplant (dyne $\cdot \mathrm{s} / \mathrm{cm}^{5}$ ) & $234 \pm 142$ & $261 \pm 171$ & $211 \pm 109$ & 0.084 \\
\hline
\end{tabular}

Values are mean \pm SD, $\mathrm{n}(\%)$

*Only available in patients with history of COPD.

CABG, coronary artery bypass graft; COPD, chronic obstructive pulmonary disease; eGFR, estimated glomerularfiltration rate; FEV ${ }_{1}$, forced expiratory volume in $1 \mathrm{~s}$; LVEF, left ventricular ejection fraction; PVR, pulmonary vascular resistance; SPAP, systolic pulmonary artery pressure; STS-PROM, Society of Thoracic Surgeons predicted risk of mortality; SVR, Systemic vascular resistance.

were in the non-TEA group. The 30-day/in-hospital mortality rate was significantly higher in the non-TEA group $(22.9 \%)$ compared with the TEA group (2.7\%), $\mathrm{p}<0.001$.

\section{Late outcomes}

Median follow-up of the study population was 12 (9-24) months, with no differences between the TEA (12 (7-22) months) and non-TEA (13 (12-33) months) groups, $\mathrm{p}=0.12$. Survival curves up to 1 -year follow-up are shown in figure 2.
Although there were no differences in late cardiovascular events or mortality beyond the periprocedural period, 1-year mortality remained significantly higher in the non-TEA group as compared with the TEA group ( $31.1 \%$ vs $10.8 \%, p=0.005)$. Univariable and multivariable predictors of cumulative late mortality are shown in table 4 . The independent predictors of cumulative late mortality in the multivariable analysis were the STS score (HR: 1.10 for each increase of $1 \%, 95 \%$ CI 1.01 to $1.20, p=0.027)$ and the non-use of TEA (HR: 2.39, 95\% CI 1.04 to 5.49, $\mathrm{p}=0.039$ ). 
Figure 1 Postoperative pain scores at different time periods, grouped according to the use of thoracic epidural analgesia TEA: thoracic epidural analgesia.

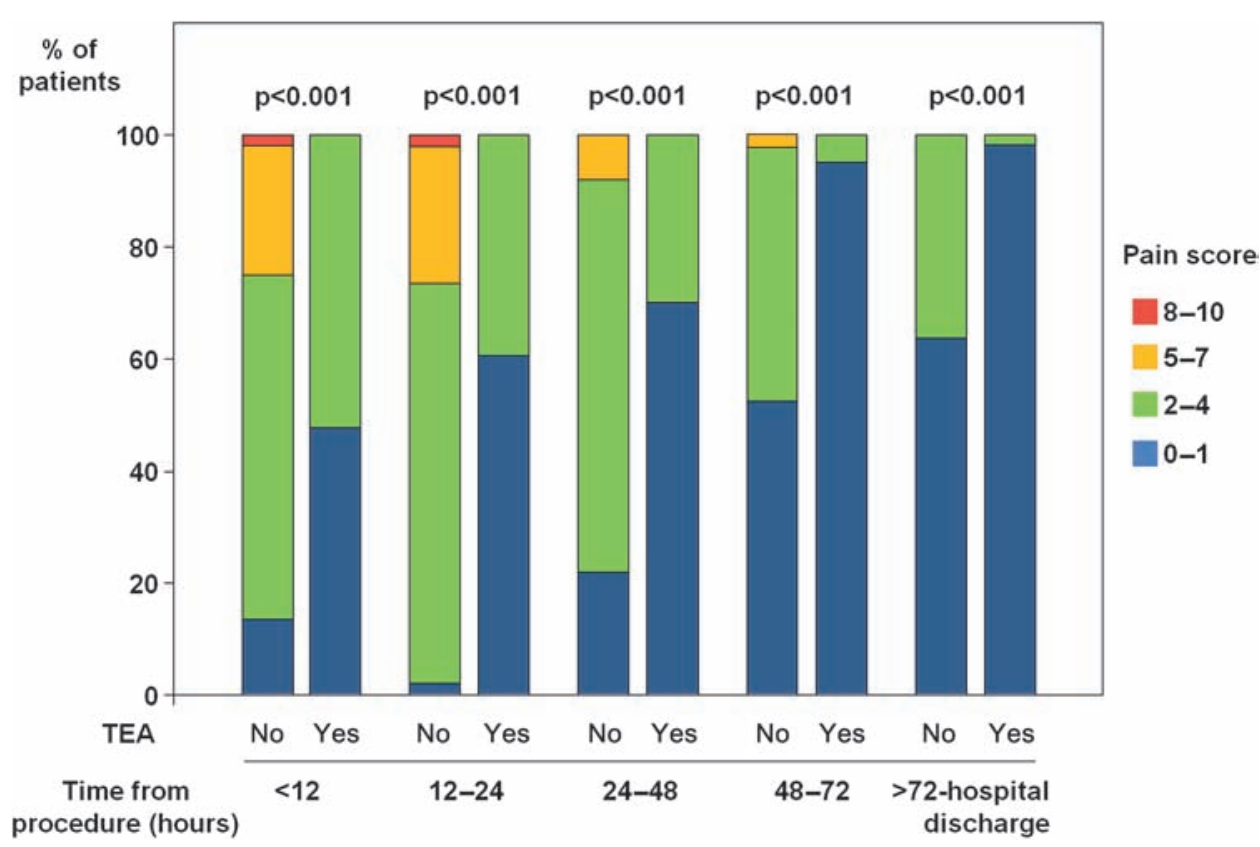

\section{Propensity score-matched cohort}

There were no differences in baseline characteristics between TEA and non-TEA groups among the 100 patients (TEA $=50$, non-TEA $=50$ ) included in the propensity score-matched cohort (table 5). Periprocedural and late events of the propensitymatched cohort are shown in table 6. Similar to the global study population analyses, TEA was associated with a lower rate of respiratory complications $(p<0.001)$, NOAF $(p<0.001)$, and a smaller increase in CK-MB $(\mathrm{p}=0.038)$. The 30 -day/in-hospital and 1-year mortality rates were lower in the TEA group $(p<0.05)$. The Kaplan-Meier survival curves for the propensity score-matched TEA and non-TEA groups are shown in figure 3 .

\section{DISCUSSION}

Several studies have shown that TEA is very effective in ensuring appropriate pain control following thoracic surgery, and some authors consider this anaesthesic technique to be the

Table 2 Acute and late outcomes, according to the use of thoracic epidural analgesia

\begin{tabular}{|c|c|c|c|c|}
\hline \multirow[b]{2}{*}{ Variables } & \multirow[b]{2}{*}{$\begin{array}{l}\text { Study population } \\
n=135\end{array}$} & \multicolumn{2}{|c|}{ Thoracic epidural analgesia } & \multirow[b]{2}{*}{ p Value } \\
\hline & & $\begin{array}{l}\text { No } \\
n=61\end{array}$ & $\begin{array}{l}\text { Yes } \\
n=74\end{array}$ & \\
\hline \multicolumn{5}{|l|}{ 30-day/in-hospital outcomes } \\
\hline Orotracheal reintubation & $16(11.9)$ & $14(22.9)$ & $2(2.7)$ & $<0.001$ \\
\hline Tracheostomy & $6(4.4)$ & $6(9.8)$ & 0 & 0.007 \\
\hline Pneumonia & $11(8.1)$ & $9(14.8)$ & $2(2.7)$ & 0.022 \\
\hline Respiratory complications* & $22(16.3)$ & 20 (32.8) & $2(2.7)$ & $<0.001$ \\
\hline Sepsis & $12(8.9)$ & $10(16.4)$ & $2(2.7)$ & 0.006 \\
\hline Haemodialysis & $3(2.2)$ & $1(1.6)$ & $2(2.7)$ & 0.677 \\
\hline Stroke & $7(5.2)$ & $3(4.9)$ & $4(5.4)$ & 1.00 \\
\hline Myocardial infarction & $2(1.5)$ & $2(3.3)$ & 0 & 0.202 \\
\hline Peak CK-MB (ug/l) & $22.0(16.1-32.0)$ & $26.5(19.1-37.6)$ & $19.8(15.0-30.0)$ & 0.002 \\
\hline Peak cardiac troponin T (ug/l) & $0.74(0.51-1.04)$ & $0.80(0.52-1.34)$ & $0.73(0.47-0.93)$ & 0.013 \\
\hline New-onset atrial fibrillation & $38(28.1)$ & $28(45.9)$ & $10(13.5)$ & $<0.001$ \\
\hline Major bleeding & $23(17.0)$ & $13(21.3)$ & $10(13.5)$ & 0.253 \\
\hline Hospital length (days, IQR) & $8(7-13)$ & $10(7-16)$ & $8(6-10)$ & 0.015 \\
\hline 30-day death & $14(10.3)$ & $12(19.7)$ & $2(2.7)$ & 0.002 \\
\hline In-hospital death & $16(11.9)$ & $14(22.9)$ & $2(2.7)$ & $<0.001$ \\
\hline 30 day/in-hospital death & $16(11.9)$ & $14(22.9)$ & $2(2.7)$ & $<0.001$ \\
\hline \multicolumn{5}{|c|}{ Late (>30-day/in-hospital to 1 -year) outcomes } \\
\hline Stroke & $1(0.7)$ & 0 & $1(1.4)$ & 1.00 \\
\hline Myocardial infarction & $1(0.7)$ & $1(1.6)$ & 0 & 0.444 \\
\hline Death & $11(8.1)$ & $5(8.2)$ & $6(8.1)$ & 0.750 \\
\hline \multicolumn{5}{|l|}{ Late (1-year) cumulative outcomes } \\
\hline Stroke & $8(5.9)$ & $3(4.9)$ & $5(6.8)$ & 0.729 \\
\hline Myocardial infarction & $3(2.2)$ & $3(4.9)$ & 0 & 0.089 \\
\hline Death & $27(20.0)$ & $19(31.1)$ & $8(10.8)$ & 0.005 \\
\hline
\end{tabular}

Values are mean $\pm \mathrm{SD}, \mathrm{n}(\%)$ or median (IQR).

*Pneumonia or respiratory failure leading to reintubation and/or tracheostomy.

CK-MB: Creatine kinase-MB. 
Table 3 Characteristics of patients who died at 30 days or in-hospital $(\mathrm{n}=16)$

\begin{tabular}{lclcl}
\hline Age & $\begin{array}{l}\text { STS-PROM } \\
\text { score (\%) }\end{array}$ & $\begin{array}{l}\text { Epidural } \\
\text { analgesia }\end{array}$ & $\begin{array}{l}\text { Time to death } \\
\text { (days from } \\
\text { procedure) }\end{array}$ & Cause of death \\
\hline 71 & 8.1 & No & 4 & $\begin{array}{l}\text { Mesenteric ischaemia } \\
\text { (septic shock) }\end{array}$ \\
72 & 10.1 & Yes & 10 & Ischaemic colitis \\
76 & 7.5 & No & 2 & Cardiogenic shock \\
77 & 6.9 & No & 27 & ARDS \\
79 & 11.5 & Yes & 2 & Cardiogenic shock \\
81 & 3.3 & No & 16 & ARDS \\
85 & 5.3 & No & 28 & Sudden death \\
85 & 13.4 & No & 4 & Cardiogenic shock \\
85 & 12.1 & No & 17 & Pneumonia (septic shock) \\
85 & 26.1 & No & 44 & Respiratory failure \\
86 & 6.1 & No & 13 & Cardiac failure \\
86 & 21.4 & No & 15 & Pneumonia (septic shock) \\
88 & 5.4 & No & 15 & Pneumonia (septic shock) \\
88 & 6.3 & No & 10 & Respiratory failure \\
96 & 15.3 & No & 3 & Cardiogenic shock \\
98 & 21.9 & No & 35 & Cardiogenic shock \\
\hline
\end{tabular}

STS-PROM: Society of Thoracic Surgeons predicted risk of mortality; ARDS: acute respiratory distress syndrome.

gold standard for postoperative analgesia following thoracic interventions. $^{8-12} 16$ Since lateral thoracotomy may be more painful than mid-sternotomy due to rib spreading and intercostal nerve injury, ${ }^{17}$ optimization of postoperative analgesia might be even more important in such cases. Nonetheless, the use of TEA in patients undergoing TA-TAVI has been limited to a single case report, ${ }^{12}$ and no studies, to date, have evaluated the efficacy and safety of this technique of anaesthesia in this setting. The present study showed that TEA was highly effective in providing postoperative analgesia following TA-TAVI. About $50 \%$ of the patients treated with TEA experienced either no pain or only minimal pain within the first $48 \mathrm{~h}$ following the procedure, and $>90 \%$ at later time-points, and these pain score levels were far lower than those observed in patients treated with intercostal local analgesia.

Some concerns have been raised about potential complications associated with TEA, such as epidural haematoma in the setting of cardiac surgery, especially because of the use of antithrombotic therapies. ${ }^{18}$ However, several studies have shown that TEA is safe in this setting, ${ }^{8-11} 18$ and recent studies have also suggested that anticoagulant therapy is safe in the presence of, or upon removal of, an epidural catheter. ${ }^{19}{ }^{20}$ Consistent with these previous reports, we observed no local complications associated with TEA despite the use of antithrombotic therapy both before and after insertion of the epidural catheter. Concerns have also been raised regarding the use of epidural anaesthesia in patients with aortic stenosis because of the risk of severe hypotension. However, there have been several reports on the safety of using epidural anaesthesia for non-cardiac and cardiac surgery in the presence of aortic stenosis, ${ }^{21-23}$ and the present study also showed that this approach was not associated with any significant haemodynamic complication in patients undergoing TA-TAVI.

The use of TEA has been associated with a lower rate of cardiovascular complications following cardiac or thoracic surgery. ${ }^{9-11}$ Several studies have shown a significant reduction in NOAF after cardiac surgery, most likely due to the sympathicolytic effects of TEA. We recently reported that NOAF is a frequent complication following TAVI, especially with the TA approach. ${ }^{24}$ The present study showed that TEA was associated with a significant reduction in AF episodes, with more than a fivefold decrease in the incidence of NOAF after TA-TAVI. In addition, some studies have suggested a reduction in myocardial ischaemia and infarction with epidural analgesia following cardiac and non-cardiac surgery. ${ }^{8-11}$ We have previously shown that TA-TAVI is systematically associated with some degree of myocardial injury as evaluated by cardiac biomarker rise. ${ }^{25}$ While puncture of the left ventricular apex is probably the main cause of post-procedural cardiac biomarker rise, the reduction in myocardial injury with TEA observed in the present study suggests that other mechanisms are also involved. Most patients
Figure 2 Kaplan-Meier survival curves at 12-month follow-up in patients with and without thoracic epidural analgesia during the TA-TAVI procedure TEA: thoracic epidural analgesia.

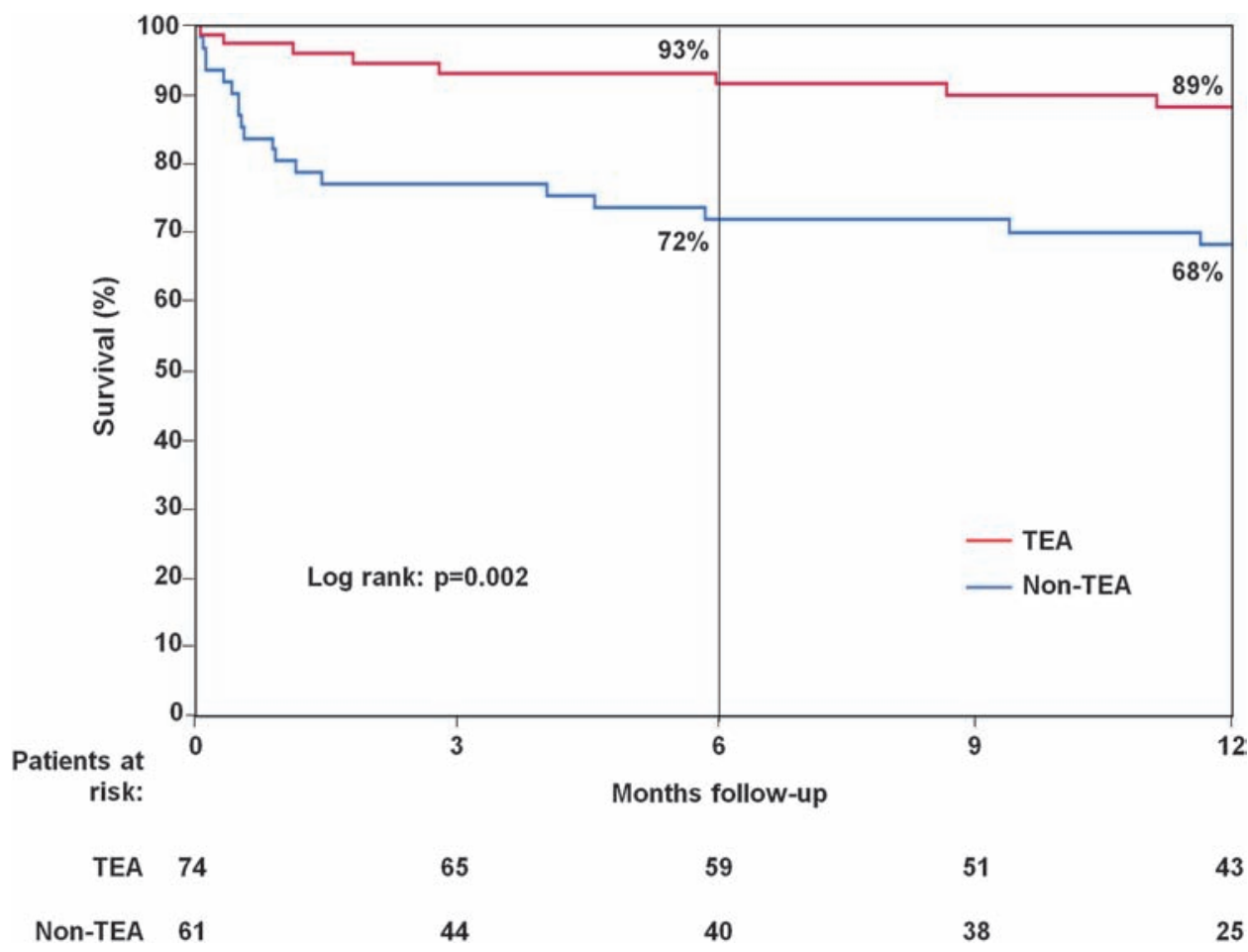


Table 4 Univariable and multivariable predictors of cumulative late mortality

\begin{tabular}{lllllll}
\hline & \multicolumn{3}{l}{ Univariable model } & & & Multivariable model \\
& HR (95\% Cl) & p Value & & HR (95\% Cl) & p Value \\
\hline eGFR $<60 \mathrm{ml} / \mathrm{min}$ & $2.27(1.03$ to 4.98$)$ & 0.041 & & $2.22(0.86$ to 5.76$)$ & 0.099 \\
STS-PROM score (\%) & $1.09(1.04 \text { to } 1.16)^{*}$ & 0.001 & & $1.10(1.01 \text { to } 1.20)^{*}$ & 0.027 \\
Frailty & $2.44(1.05$ to 5.70$)$ & 0.039 & & $1.96(0.82$ to 4.67$)$ & 0.129 \\
No thoracic epidural analgesia & $2.59(1.19$ to 5.65$)$ & 0.016 & & $2.39(1.04$ to 5.49$)$ & 0.039 \\
\hline
\end{tabular}

*For each increase of $1 \%$.

eGFR: estimated glomerularfiltration rate; STS-PROM: Society of Thoracic Surgeons predicted risk of mortality.

with severe aortic stenosis have some degree of myocardial hypertrophy, and the hyperadrenergic response associated with non-optimal analgesia following TA-TAVI might be associated with higher perioperative myocardial oxygen consumption leading to myocardial ischaemia and greater cardiac biomarker rise. Also, the higher incidence of NOAF episodes in the absence of TEA may have contributed to the greater degree of myocardial injury observed in this group.

Thoracic surgery has been associated with a postoperative worsening in pulmonary function due to diaphragmatic dysfunction, decreased chest wall compliance and pain-limited inspiration, and this might translate into a higher incidence of postoperative atelectasia pneumonia and hypoxaemia. ${ }^{8}{ }^{26}$ Indeed, the deleterious effects of thoracotomy on pulmonary function might be even more pronounced in elderly patients, who frequently exhibit a reduced pulmonary capacity prior to the intervention. ${ }^{27}$ The use of TEA in thoracic and cardiac surgery has been associated with a significant improvement in postoperative pulmonary function, shorter time to extubation, and a lower rate of pulmonary complications, such as pneumonia or

Table 5 Baseline characteristics of the propensity score-matched cohort $(n=100)$, according to the use of thoracic epidural analgesia

\begin{tabular}{|c|c|c|c|}
\hline & \multicolumn{2}{|c|}{$\begin{array}{l}\text { Thoracic epidural } \\
\text { analgesia }\end{array}$} & \multirow[b]{2}{*}{ p Value } \\
\hline & $\begin{array}{l}\text { No } \\
n=50\end{array}$ & $\begin{array}{l}\text { Yes } \\
n=50\end{array}$ & \\
\hline Age, years & $80 \pm 9$ & $78 \pm 8$ & 0.281 \\
\hline Males & $22(44.0)$ & $18(36.0)$ & 0.541 \\
\hline Diabetes & $17(34.0)$ & $19(38.0)$ & 0.835 \\
\hline Dyslipidemia & $42(84.0)$ & $43(86.0)$ & 1.00 \\
\hline Hypertension & $47(94.0)$ & $47(94.0)$ & 1.00 \\
\hline Coronary artery disease & $33(66.0)$ & $35(70.0)$ & 0.831 \\
\hline Previous myocardial infarction & $23(46.0)$ & $21(42.0)$ & 0.841 \\
\hline Previous atrial fibrillation & $15(30.0)$ & $13(26.0)$ & 0.824 \\
\hline Prior CABG & $21(42.0)$ & $18(36.0)$ & 0.682 \\
\hline Prior stroke & $2(4.0)$ & $4(8.0)$ & 0.678 \\
\hline Peripheral vascular disease & $19(38.0)$ & $27(54.0)$ & 0.160 \\
\hline COPD & $16(32.0)$ & $16(32.0)$ & 1.00 \\
\hline eGFR $<60 \mathrm{ml} / \mathrm{min}$ & $31(62.0)$ & $35(70.0)$ & 0.527 \\
\hline STS-PROM score (\%) & $9.1 \pm 5.5$ & $8.4 \pm 3.8$ & 0.567 \\
\hline Frailty & $8(16.0)$ & $9(18.0)$ & 1.00 \\
\hline Severely calcified or porcelain aorta & $14(28.0)$ & $16(32.0)$ & 0.828 \\
\hline Mean aortic gradient (mm Hg) & $42.3 \pm 16.6$ & $40.4 \pm 17.0$ & 0.566 \\
\hline Aortic valve area $\left(\mathrm{cm}^{2}\right)$ & $0.62 \pm 0.16$ & $0.67 \pm 0.23$ & 0.266 \\
\hline $\operatorname{LVEF}(\%)$ & $55 \pm 13$ & $54 \pm 12$ & 0.809 \\
\hline $\operatorname{LVEF}<40$ & $6(12.0)$ & $9(18.0)$ & 0.579 \\
\hline SPAP $(\mathrm{mm} \mathrm{Hg})$ & $46 \pm 13$ & $43 \pm 13$ & 0.403 \\
\hline Moderate/severe mitral regurgitation & $19(38.0)$ & $14(28.0)$ & 0.395 \\
\hline
\end{tabular}

Values are mean $\pm \mathrm{SD}, \mathrm{n}(\%)$.

CABG, coronary artery bypass graft; COPD, chronic obstructive pulmonary disease; eGFR, estimated glomerularfiltration rate; LVEF, left ventricular ejection fraction; PAP, systolic pulmonary artery pressure; STS-PROM, Society of Thoracic Surgeons predicted risk of mortality. respiratory insufficiency. ${ }^{8} 2328$ The present study showed that TEA was associated with a more rapid extubation time and a dramatic reduction in pulmonary complications, such as nosocomial pneumonia, or the need for orotracheal reintubation or tracheostomy due to respiratory failure following TA-TAVI. Of note, pulmonary complications were the cause of death in about half of the patients who died during the postoperative period, and all fatal pulmonary complications occurred in patients who did not receive TEA for perioperative analgesia. This, in turn, translated into a risk of perioperative mortality that was approximately nine times greater among those patients not receiving TEA (approximately six times greater after propensity matching), strongly suggesting an important role for TEA in reducing pulmonary complications and improving clinical outcomes (including survival) following TA-TAVI. The use of TEA has been associated with an improvement in survival following cardiac surgery and intermediate to high-risk noncardiac surgery. ${ }^{9-11} 29$ This postoperative mortality reduction with TEA has been partially attributed to a reduction in surgical stress response, cardiac complications, pulmonary complications, infectious complications and postoperative pain.

The dramatic effect of TEA on mortality in our study might be related to the characteristics of the study population, with a combination of very advanced age, severe aortic stenosis and a high prevalence of major cardiac and non-cardiac comorbidities, such as cardiac failure, pulmonary hypertension, chronic obstructive pulmonary disease or frailty. Thoracotomy probably has a more pronounced deleterious impact in this very high-risk group of patients. Interestingly, Kempfert et a ${ }^{30}$ have recently reported that a reduced pulmonary capacity was the most important predictive factor of worse outcomes in a large series of patients undergoing TA-TAVI. It is therefore not surprising that any measure leading to a reduction of the negative effects of thoracotomy, such as the use of TEA, translates into major improvement in clinical outcomes. Recent large multicenter TAVI studies have reported 30-day and 1-year mortality rates associated with TA-TAVI of $\sim 12 \%$ and $\sim 30 \%$, respectively, ${ }^{3-7}$ rates that are somewhat higher than those reported for patients treated via the transfemoral approach in the same studies. Also, the PARTNER investigators have reported that among patients at high risk of surgical complications, TA-TAVI did not result in any measurable quality-of-life benefits at 1- and 6-month followup, as compared with surgical aortic valve replacement, findings that differed from the substantial early quality-of-life benefits of TAVI among patients suitable for the transfemoral approach. ${ }^{31}$ While these findings might be explained in part by the higher risk profile of the patients treated by TA approach, the present study provides important insight into the prognostic importance of postoperative pain management in such patients. The absence of fatal pulmonary complications and the very low perioperative mortality rate $(<3 \%)$ in the TEA group as compared with the non-TEA group $(>20 \%)$ strongly suggest that optimisation of postoperative care/analgesia might be a key factor to improve 
Table 6 Acute and late outcomes of the propensity score-matched cohort $(n=100)$, according to the use of thoracic epidural analgesia

\begin{tabular}{|c|c|c|c|}
\hline \multirow[b]{2}{*}{ Variables } & \multicolumn{2}{|c|}{ Thoracic epidural analgesia } & \multirow[b]{2}{*}{ p Value } \\
\hline & $\begin{array}{l}\text { No } \\
n=50\end{array}$ & $\begin{array}{l}\text { Yes } \\
n=50\end{array}$ & \\
\hline \multicolumn{4}{|l|}{ 30-day/in-hospital outcomes } \\
\hline Orotracheal reintubation & $10(20.0)$ & $1(2.0)$ & 0.004 \\
\hline Tracheostomy & $5(10.0)$ & 0 & 0.056 \\
\hline Pneumonia & $8(16.0)$ & $2(4.0)$ & 0.046 \\
\hline Respiratory complications* & $16(32.0)$ & $2(4.0)$ & $<0.001$ \\
\hline Sepsis & $9(18.0)$ & $2(4.0)$ & 0.025 \\
\hline Stroke & $3(6.0)$ & $3(6.0)$ & 1.00 \\
\hline Myocardial infarction & $1(2.0)$ & 0 & 0.315 \\
\hline Peak CK-MB (ug/l) & $24.5(18.1-32.9)$ & $19.8(15.3-30.0)$ & 0.038 \\
\hline Peak cardiac troponin T (ug/l) & $0.74(0.52-1.32)$ & $0.76(0.50-0.95)$ & 0.343 \\
\hline New-onset atrial fibrillation & $26(52.0)$ & $8(16.0)$ & $<0.001$ \\
\hline Major bleeding & $10(20.0)$ & $8(16.0)$ & 0.569 \\
\hline Hospital length (days, IQR) & $10(7-16)$ & $8(7-10)$ & 0.058 \\
\hline 30-day death & $10(20.0)$ & $2(4.0)$ & 0.014 \\
\hline In-hospital death & $12(24.0)$ & $2(4.0)$ & 0.004 \\
\hline 30 day/in-hospital death & $12(24.0)$ & $2(4.0)$ & 0.004 \\
\hline \multicolumn{4}{|c|}{ Late (>30-day/in-hospital to 1 -year) outcomes } \\
\hline Stroke & 0 & $1(2.0)$ & 1.00 \\
\hline Myocardial infarction & 0 & 0 & - \\
\hline Death & $3(6.0)$ & $4(8.0)$ & 1.00 \\
\hline \multicolumn{4}{|l|}{ Late (1 year) cumulative outcomes } \\
\hline Stroke & $3(6.0)$ & $4(6.0)$ & 1.00 \\
\hline Myocardial infarction & $1(2.0)$ & 0 & 0.315 \\
\hline Death & $15(30.0)$ & $6(12.0)$ & 0.026 \\
\hline
\end{tabular}

clinical outcomes in the very high-risk group of patients undergoing TA-TAVI. This is further supported by the fact that, in addition to the STS score, the non-use of TEA remained the most important predictor of mortality at midterm follow-up. The confirmation of these results in larger studies would represent a paradigm shift in the perioperative management of such patients that could yield substantial reductions in morbidity and improved short- and long-term survival following TA-TAVI.

\section{Study limitations}

The main limitation of this study is its non-randomised nature. However, we do not believe that confounding was the main
Figure 3 Kaplan-Meier survival curves at 12-month follow-up in patients with and without thoracic epidural analgesia during the TA-TAVI procedure for the propensity scorematched cohort $(n=100)$ TEA: thoracic epidural analgesia.

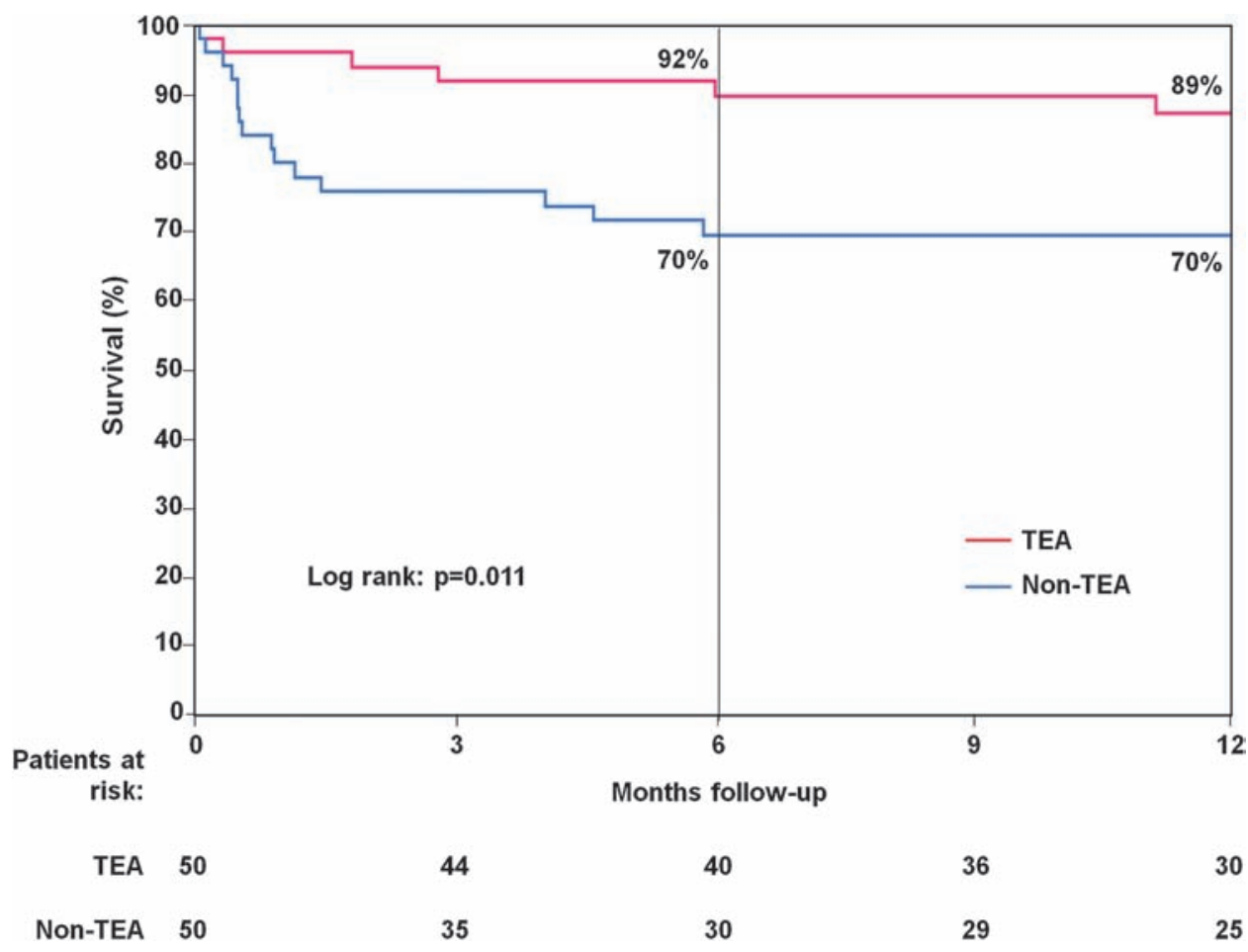


explanation for our findings since the selection of patients for TEA was based mainly on the comfort level of the anaesthesiologist with this technique, which led to similar patient characteristics in the two groups. The fact that our results were similar in both risk-adjusted and propensity-matched analyses lends further support to the validity of our findings. Nonetheless, future randomised studies will be necessary to confirm these findings. Although no complications were associated with the use of the epidural catheter, larger studies are needed to further demonstrate the safety of TEA in TA-TAVI procedures.

In conclusion, perioperative analgesia management with TEA was associated with a dramatic reduction in pulmonary and cardiovascular complications and death following TA-TAVI for the treatment of severe aortic stenosis in patients considered to be at very high or prohibitive surgical risk. These findings highlight the importance of the potential negative effects of thoracotomy in this challenging group of elderly patients with multiple comorbid conditions. The results of this study strongly suggest that the optimisation of the perioperative management, and particularly postoperative analgesia following TA-TAVI, would represent a major step forward in improving the results associated with these procedures.

Contributors All authors have read and approved submission of the manuscript. All authors have contributed to this work as follows: (1) substantial contributions to the conception and design, acquisition of data or analysis and interpretation of data; (2) drafting the article or revising it critically for important intellectual content; and (3) final approval of the version to be published.

Funding Dr IJA-S received support from the Institute of Heart Sciences (ICICOR, Clinical Hospital of Valladolid, Spain).

Competing interests Dr ED is consultant for Edwards Lifesciences; Dr DJC has received research grant support from Edwards Lifesciences and Medtronic Inc. Dr JR-C is consultant for Edwards Lifesciences and St Jude Medical.

Ethics approval The study protocol was performed in accordance with the institutional ethics committee.

Provenance and peer review Not commissioned; externally peer reviewed.

\section{REFERENCES}

1. Rodés-Cabau J. Transcatheter aortic valve implantation: current and future approaches. Nat Rev Cardiol 2012;9:15-29.

2. Vahanian A, Himbert D, Brochet E. Transcatheter valve implantation for patients with aortic stenosis. Heart 2010;96:1849-56

3. Webb JG, Altwegg L, Boone $\mathrm{RH}$, et al. Transcatheter aortic valve implantation: impact on clinical and valve-related outcomes. Circulation 2009:119:3009-16.

4. Thomas M, Schymik G, Walther T, et al. One-year outcomes of cohort 1 in the Edwards SAPIEN Aortic Bioprosthesis European Outcome (SOURCE) registry: the European registry of transcatheter aortic valve implantation using the Edwards SAPIEN valve. Circulation 2011;124:425-33.

5. Gilard $\mathbf{M}$, Eltchaninoff $\mathrm{H}$, lung $\mathrm{B}$, et al. Registry of transcatheter aortic-valve implantation in high-risk patients. N Engl J Med 2012;366:1705-15.

6. Moat N, Ludman P, de Belder MA, et al. Long term outcomes after transcathete aortic valve implantation in high risk patients with severe aortic stenosis. The UK TAVI registry. J Am Coll Cardiol 2011:58:2130-8.

7. Smith CR, Leon MB, Mack MJ, et al. Transcatheter versus surgical aortic-valve replacement in high-risk patients. N Engl J Med 2011;364:2187-98.

8. Joshi GP, Bonnet $F$, Shah $R$, et al. A systematic review of randomized trials evaluating regional techniques for post-thoracotomy analgesia. Anesth Analg 2008;107:1026-40.
9. Moraca RJ, Sheldon DG, Thirlby RC, et al. The role of epidural anesthesia and analgesia in surgical practice. Ann Surg 2003;238:663-73.

10. Svircevic V, van Dijk D, Nierich AP, et al. Meta-analysis of thoracic epidural anesthesia versus general anesthesia for cardiac surgery. Anesthesiology 2011;114:271-82.

11. Bignami E, Landoni G, Biondi-Zoccai GG, et al. Epidural analgesia improves outcome in cardiac surgery: a meta-analysis of randomized controlled trials. J Cardiothorac Vasc Anesth 2010;24:586-97.

12. Mukherjee C, Walther T, Borger MA et al. Awake transapical aortic valve implantation using thoracic epidural anesthesia. Ann Thorac Surg 2009;88:992-4.

13. Rodés-Cabau J, Dumont E, De LaRochellière R, et al. Feasibility and initial results of percutaneous aortic valve implantation including selection of the transfemoral or transapical approach in patients with severe aortic stenosis. Am J Cardiol 2008:102:1240-6.

14. Horlocker $\mathbf{T}$, Wedel DJ, Rowlingson JC, et al. Regional anesthesia in the patien receiving antithrombotic or thrombolytic therapy: American Society of Regional Anesthesia and Pain Medicine Evidence-Based Guidelines. Reg Anesth Pain Med 2010;35:64-101

15. Leon MB, Piazza N, Nikolsky E, et al. Standardized endpoint definitions for Transcatheter Aortic Valve Implantation clinical trials: a consensus report from the Valve Academic Research Consortium. J Am Coll Cardiol 2011:57:253-69.

16. Hemmerling TM, Djaiani G, Babb P, et al. The use of epidural analgesia in cardiac surgery should be encouraged. Anesth Analg 2006;103:1592-3.

17. Walther T, Falk V, Metz S, et al. Pain and quality of life after minimally invasive versus conventional cardiac surgery. Ann Thorac Surg 1999;67:1643-7.

18. Gogarten $\mathbf{W}$. The influence of new antithrombotic drugs on regional anesthesia. Curr Opin Anaesthesiol 2006;19:545-50.

19. Green L, Machin SJ. Managing anticoagulated patients during neuraxial anaesthesia. Br J Haematol 2010:149:195-208.

20. Liu SS, Buvanendran A, Viscusi ER, et al. Uncomplicated removal of epidural catheters in 4365 patients with international normalized ratio greater than 1.4 during initiation of warfarin therapy. Reg Anesth Pain Med 2011;36:231-5.

21. Ho MC, Beathe JC, Sharrock NE, et al. Hypotensive epidural anesthesia in patients with aortic stenosis undergoing total hip replacement. Reg Anesth Pain Med 2008; 33:129-33.

22. Ioscovich AM, Goldszmidt E, Fadeev AV, et al. Peripartum anesthetic management of patients with aortic valve stenosis: a retrospective study and literature review. In J Obstet Anesth 2009;18:379-86.

23. Bracco D, Noiseux N, Dubois MJ, et al. Epidural anesthesia improves outcome in cardiac surgery: a single-center study of a 1293-patient cohort. Heart Surg Forum 2007; 10:E449-58.

24. Amat-Santos IJ, Rodés-Cabau J, Urena M, et al. Incidence, predictive factors, and prognostic value of new-onset atrial fibrillation following transcatheter aortic valve implantation. J Am Coll Cardiol 2012;59:178-88.

25. Rodés-Cabau J, Gutierrez M, Bagur R, et al. Incidence, predictive factors, and prognostic value of myocardial injury following uncomplicated transcatheter aortic valve implantation. J Am Coll Cardiol 2011;57:1988-99.

26. Richardson J, Sabanathan S, Shah R, et al. Post-thoracotomy spirometric lung function: the effect of analgesia. A review. J Cardiovasc Surg (Torino) 1999:40:445-56

27. Scarlata $\mathbf{S}$, Pedone $\mathrm{C}$, Conte $\mathrm{ME}$, et al. Accuracy of spirometry in diagnosing pulmonary restriction in elderly people. J Am Geriatr Soc 2009:57:2011-17.

28. Ballantyne JC, Carr DB, deFerranti S, et al. The comparative effects of postoperative analgesic therapies on pulmonary outcome: cumulative meta-analyses of randomized controlled trials. Anesth Analg 1998;86:598-612.

29. Wijeysundera DN, Beattie WS, Austin PC, et al. Epidural anaesthesia and survival after intermediate-to-high risk non-cardiac surgery: a population-based cohort study. Lancet 2008:372:562-9.

30. Kempfert J, Rastan A, Holzhey D. Transapical aortic valve implantation: analysis of risk factors and learning experience in 299 patients. Circulation 2011;124(11 Suppl): S124-9.

31. Reynolds MR, Magnuson EA, Wang K, et al. Health-related quality of life after transcatheter or surgical aortic valve replacement in high risk patients with severe aortic stenosis: results from the PARTNER trial (cohort A). J Am Coll Cardiol. In press 
that the linked article (reference 6) starts on page 1483. This is an error, it should say the starting page is 1583 .

doi:10.1136/heartjnl-2012-302185corr1

\section{CORRECTIONS}

Dworakowski R, Wendler O. Optimal pain management after aortic valve implantation: an opportunity to improve outcomes after transapical access in the future? Heart 2012;98:1541-1542. This editorial states 